\title{
Elementary students' attitudes towards STEM and 21st-century skills
}

\author{
Riki Perdana, An-Nisa Apriani, Rino Richardo, Endi Rochaendi, Chahya Kusuma \\ Faculty of Teacher Training and Education, Alma Ata University, Indonesia
}

\section{Article Info \\ Article history: \\ Received Dec 23, 2020 \\ Revised Jun 28, 2021 \\ Accepted Jul 12, 2021 \\ Keywords: \\ 21st-century skill \\ Elementary school \\ STEM \\ Students' attitude}

\begin{abstract}
Science, Technology/Engineering and Math (STEM) and 21st-century learning are very important to be applied to all students starting from their early age, including at the elementary school level. This study aimed to describe students' attitudes towards STEM and 21st-century skills according to gender and education level. This research was descriptive quantitative by explaining and comparing the results of the questionnaires given to students. Student attitudes were described based on domain of STEM, 21st-century skills, gender, and student grade level. The respondent of this study was 130 elementary students who were obtained randomly from one of the elementary schools in Yogyakarta, Indonesia. The results showed that based on the science domain, the mean score of the students was 3.23 (moderate) while mathematics domain obtained was 3.21 (moderate); technology/engineering domain obtained was 3.68 (moderate) and 21 st-century skill domain obtained was 3.65 (moderate). According to gender, there was a significant difference between the attitudes of male and female students towards STEM and 21stcentury skills. However, there was no significant difference based on the grade of students. Based on these findings, it is suggested that teachers or policymakers should have comprehended the student attitudes before implemented the STEM-based learning and 21st-century skills. These findings can be used to create STEM and 21st-century learning.
\end{abstract}

This is an open access article under the CC BY-SA license.

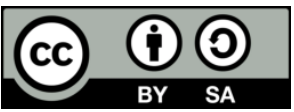

\section{Corresponding Author:}

Riki Perdana

Faculty of Teacher Training and Education

Alma Ata University

55183 Kasihan, Bantul, Daerah Istimewa Yogyakarta, Indonesia

Email: rikiperdana@almaata.ac.id

\section{INTRODUCTION}

There are many important things that students have to possessed in this era, namely developing inquiry skills and stimulating positive attitudes towards Science, Technology/Engineering and Math (STEM) education [1]. Educators and the school community need to integrate STEM in learning because it can benefit the national economy [2]. STEM integration aims to combine multiple disciplines as a way to engage students in topics of interest while teaching critical thinking and core content knowledge for future success in STEM careers [3]. However, at the end of the learning phase at primary school level, many students find science boring, difficult, and irrelevant to their lives [4]. For that reason, the number of students studying and entering STEM fields is decreasing, even though there are more and more STEM jobs available [5].

The low interest of students in understanding STEM remains one of the main concerns of the stakeholders in this era [6]. In addition, students' attitudes and work interests in the STEM field continue to change throughout the years both in their primary and secondary schools [7]. Students' attitudes towards STEM subjects vary widely and generally decline during the first year of high school due to number of 
changes in their attitudes [8]. In fact, there are many things needed by the students who want to work in the fields of STEM to advance global competitiveness and economic growth [9].

To motivate them to continue their studies and careers in the STEM field, developing an understanding of the interesting characteristics of STEM and describing individuals working in the STEM field can be an important steps to take [10]. STEM education contributes to transforming students into producers, not just recipients of knowledge and technology, and encourages critical, creative and problemsolving thinking [11]. Therefore STEM education has become a central topic in the field of education in relation to learning outcomes [12].

Based on the previous explanation, a study that focuses more on the development of attitudes in the context of teaching science and techniques integrated informal learning is needed [13]. A better understanding of student attitudes and the relationship between learning choices and future work choices will lead to changes in learning to support students, particularly in these difficult subjects such as STEM [14]. In addition, STEM education programs targeted at younger students (basic education) have a greater positive impact [15]. To support this education, this study will describe the attitudes of elementary students towards STEM and 21st-century skills. The results of this study are expected to support STEM and 21st-century based learning policies for elementary students. This is because measuring the impact of a STEM program on student attitudes is very important in making decisions that are relevant to the design and implementation of future programs [16].

\section{RESEARCH METHOD}

This study aimed to describe students' attitudes toward Science, Technology/Engineering and Math (STEM) and 21st-century skills based on gender and student grade level. There were 130 elementary school students in grades 4, 5, and 6 who were randomly selected from a public elementary school in Yogyakarta, Indonesia. There were 70 male students and 60 female students participated in this study. The items of this study were modified according to Unfried, et al. [17].

There are 41 items of students' attitudes towards STEM and 21st-century skills divided into 8 items for the science, 11 items for technology/technique, 9 items of mathematics, and 13 items for the 21 st-century skills. All participants were asked to fill out a questionnaire that was distributed in the form. Each item consists of a scale of 1-5 which must be filled in by all participants. Table 1 shows the indicators of the test items used.

Data analysis was performed using quantitative descriptive methods. Students 'attitudes towards STEM and 21st-century skills were described in several aspects including the domain of STEM and 21stcentury skills, gender, and the students' grade. To determine the level of students' attitudes towards STEM, the rubric of the given questionnaire was grouped as seen in Table 2. 
Table 1. Indicator of items

\begin{tabular}{|c|c|c|}
\hline Domain & Indicator & Item \\
\hline \multirow[t]{9}{*}{ Math } & Mathematics is an important subject for everyday life & 1 \\
\hline & My math score was worse than others & 2 \\
\hline & In the future, I will work in mathematics & 3 \\
\hline & Math is the most difficult subject & 4 \\
\hline & In the future, I need to understand the math for my job & 5 \\
\hline & I am the type of student who is good at math & 6 \\
\hline & In the future, I will be able to do more difficult math problems & 7 \\
\hline & I can get good grades in math & 8 \\
\hline & I'm good at math & 9 \\
\hline \multirow[t]{8}{*}{ Science } & I feel comfortable when I study science & 10 \\
\hline & In the future, I want to work in science & 11 \\
\hline & I will often use science after graduating from elementary school & 12 \\
\hline & In the future, knowing science will help me make money & 13 \\
\hline & in the future, I need to understand science for my job & 14 \\
\hline & I know I can do well in science & 15 \\
\hline & Science will be important for me to work on later & 16 \\
\hline & I can understand most subjects easily, but science is difficult for me & 17 \\
\hline \multirow{24}{*}{ Engineering/Technology } & I like to imagine creating new masterpieces & 18 \\
\hline & If I learn engineering/technology, then I can find new things that people can use every day & 19 \\
\hline & I'm good at building or fixing things & 20 \\
\hline & Understanding the engineering/technology will help me make money & 21 \\
\hline & I am interested in what causes a machine to start & 22 \\
\hline & Designing works or buildings is important in my future & 23 \\
\hline & I want to know about how electronics work & 24 \\
\hline & I will choose a job that involves building activities or producing something & 25 \\
\hline & I want to be creative in my job & 26 \\
\hline & Knowing how to use math and science together will help me find useful things & 27 \\
\hline & I believe I can be successful in producing new thing & 28 \\
\hline & I can lead others to achieve goals & 29 \\
\hline & I like to help others so that they can do their best & 30 \\
\hline & I usually know how to do the right thing & 31 \\
\hline & At school and at home, I can do many things well & 32 \\
\hline & I usually act responsibly & 33 \\
\hline & I respect all my friend even though they are different from me & 34 \\
\hline & I try to help my friend & 35 \\
\hline & When I make decisions, I think about what's good for the other person & 36 \\
\hline & When things don't go the way I want, I can change my actions for the better & 37 \\
\hline & While studying, I can set my own goals & 38 \\
\hline & I can use my time wisely when working alone & 39 \\
\hline & When I have a lot of homework, I can choose what to do first & 40 \\
\hline & I can cooperate with all students, even if they are different from me & 41 \\
\hline
\end{tabular}

Table 2. Rubric of questionnaire

\begin{tabular}{cc}
\hline Range & Level \\
\hline $\mathrm{x} \leq 2.00$ & Very low \\
$2.00<\mathrm{x} \leq 3.00$ & Low \\
$3.00<\mathrm{x} \leq 4.00$ & Moderate \\
$4.00<\mathrm{x} \leq 4.50$ & High \\
$4.50<\mathrm{x} \leq 5.00$ & Very high \\
\hline
\end{tabular}

\section{RESULTS AND DISCUSSION}

This section describes the results of students' attitudes toward Science, Technology/Engineering and Math (STEM) and 21st-century skills. The instrument was analysis using SPSS. The result showed that reliability scale was high, where the alpha Cronbach value was 0.92 and the validity of the item is shown in Table 3. According to Table 3, item 2, 3, and 4 were not valid $\left(r<r_{\text {table }} 0.172\right)$ while other items were valid. 
in Table 6. On the mathematics domain, the highest mean indicator for male students is "Mathematics is an important subject for everyday life (item 1)" with a score of 4.11 (high) while the lowest indicator is "My math score was the worse than other (item 2)" with a score of 2.58 (low). Meanwhile, the highest mean indicator for female students is "In the future, I need to understand the math for my job (item 5)" with a score of 4.0 (moderate) while the lowest indicator is "My math score was the worse than others (item 2)" with a score of 2.78 (low).

On the science domain, the highest mean indicator of male students is the "I feel comfortable when I study science (item 10)" with a score of 3.94 (moderate) while the lowest is "I can understand most subjects easily, but science is difficult for me (item 17)" with a score of 2.82 (low). Meanwhile, the highest mean for female students is "I know I can do well in science (item 15)" with 3.71 (moderate) while the lowest indicator for female students is "I can understand most subjects easily, but science is difficult (item 17)" with a score 2.60 (low).

On the technological/engineering domain, the highest mean of male students is "I believe I can be successful in producing new thing (item 28)" with a score of 4.15 (high) while the lowest is "I'm good at building or fixing things (item 20)" and "I will choose a job that involves building activities or producing something (item 25)" with a score of 3.55 (moderate). Meanwhile, the highest mean for females is "Knowing how to use math and science together will help me find useful things (item 27)" with a score of 4.11 (high) while the lowest is "I'm good at building or fixing things (item 20)" with a score of 3.05 (moderate).

On the 21st-century skills domain, the highest and lowest mean indicator of male and female students are the same. The highest mean is "I respect all children my age even though they are different from me (item 34)" with a score of 4.15 (high) for males and 4.08 (high) for females. The lowest mean is "I can use my time wisely when working alone (item 39)" with a score of 3.62 (moderate) for males and 3.56 (moderate) for females. To further obtaining better understanding, the Manova test was conducted to prove whether there were significant differences in attitudes towards STEM and 21st-century skills based on gender. There are significant differences in STEM attitudes and 21st-century skills based on gender where the sig value is $(0.016<0.05)$. Table 7 shows the dimensions that show significant differences in students' attitude toward STEM and 21st-century skills based on gender.

Table 6. Students' attitude toward STEM and 21st-century skill based on gender

\begin{tabular}{cccccccccc}
\hline \multirow{2}{*}{ Item } & \multicolumn{3}{c}{ Male } & \multicolumn{2}{c}{ Female } & \multirow{2}{*}{ Item } & \multicolumn{2}{c}{ Male } & \multicolumn{2}{c}{ Female } \\
& Mean & Description & Mean & Description & & Mean & Description & Mean & Description \\
\hline 1 & 4.11 & High & 3.85 & Moderate & 22 & 3.88 & Moderate & 3.23 & Moderate \\
2 & 2.58 & Low & 2.78 & Low & 23 & 3.65 & Moderate & 3.38 & Moderate \\
3 & 2.65 & Low & 2.98 & Low & 24 & 4.04 & High & 3.65 & Moderate \\
4 & 3.04 & Moderate & 2.83 & Low & 25 & 3.55 & Moderate & 3.25 & Moderate \\
5 & 3.94 & Moderate & 4.00 & Moderate & 26 & 4.07 & High & 4.01 & High \\
6 & 2.88 & Low & 3.01 & Moderate & 27 & 3.92 & Moderate & 4.11 & High \\
7 & 3.31 & Moderate & 3.48 & Moderate & 28 & 4.15 & High & 4.08 & High \\
8 & 3.67 & Moderate & 3.70 & Moderate & 29 & 3.64 & Moderate & 3.58 & Moderate \\
9 & 3.14 & Moderate & 3.10 & Moderate & 30 & 4.24 & High & 4.00 & Moderate \\
10 & 3.94 & Moderate & 3.67 & Moderate & 31 & 3.94 & Moderate & 3.73 & Moderate \\
11 & 3.20 & Moderate & 2.92 & Low & 32 & 4.00 & Moderate & 3.80 & Moderate \\
12 & 3.62 & Moderate & 3.45 & Moderate & 33 & 3.75 & Moderate & 3.56 & Moderate \\
13 & 3.62 & Moderate & 3.48 & Moderate & 34 & 4.15 & High & 4.08 & High \\
14 & 3.54 & Moderate & 3.60 & Moderate & 35 & 3.80 & Moderate & 3.75 & Moderate \\
15 & 3.54 & Moderate & 3.71 & Moderate & 36 & 3.91 & Moderate & 3.83 & Moderate \\
16 & 3.57 & Moderate & 3.61 & Moderate & 37 & 3.97 & Moderate & 3.88 & Moderate \\
17 & 2.82 & Low & 2.60 & Low & 38 & 3.77 & Moderate & 3.58 & Moderate \\
18 & 4.10 & High & 3.60 & Moderate & 39 & 3.62 & Moderate & 3.56 & Moderate \\
19 & 3.92 & Moderate & 3.60 & Moderate & 40 & 3.87 & Moderate & 3.92 & Moderate \\
20 & 3.55 & Moderate & 3.05 & Moderate & 41 & 4.08 & High & 4.03 & High \\
21 & 3.81 & Moderate & 3.68 & Moderate & & & & & \\
& Overall male=3.68 (moderate); SD=0.42 & & Overall female=3.56 (moderate); SD=0.39
\end{tabular}

Table 7. Test between Manova

\begin{tabular}{lcccccc}
\hline Source & Dependent variable & Type III sum of squares & df & Mean square & F & Sig. \\
\hline Gender & Science & .031 & 1 & .031 & .147 & .702 \\
& Math & .210 & 1 & .210 & .489 & .486 \\
& Technology engineering & 2.723 & 1 & 2.723 & 8.255 & .005 \\
& Century skill & .415 & 1 & .415 & .962 & .329 \\
\hline
\end{tabular}




\subsection{Students' attitude toward 21st-century skill and STEM based on their grade}

In this section, the students' attitudes towards STEM and 21st-century skill were described according to their grade. There were 40 students at grade 4, 34 students at grade 5, and 54 students at grade 6 joining this study. The results can be seen in the Table 8 .

In grade 4, the highest mean of attitude toward math is "When I grow up, I need to understand the math for my job (item 5)" with a score of 4.0 (moderate) while the lowest mean is "My math score was worse than others (item 2)" with a score of 2.55 (low). The highest mean of attitude toward science is the "I feel comfortable when I study science (Item 10)" with a score of 3.62 (moderate) while the lowest is "I can understand most subjects easily, but science is difficult for me (item 10)" with a score of 2.53 (low). The highest mean of attitude toward technological/technical is "I believe I can be successful in producing new things (item 28)" with a score of 4.06 (high) while the lowest mean is "I am good at building or repairing something (item 20)" with a score 3.16 (moderate). The highest mean of 21 st-century skill is "I like to help others so they can do their best (item 30)" with a score of 4.06 (high) while the lowest is "I can lead others to reach goals (item 29)" with a score of 3.53 (moderate).

In grade 5, the highest mean for math is "In the future, I need to understand the math for my job with (item 5) with a score of 4.05 (high) while the lowest is math the hardest subject for me (item 4)" with a score of 2.79 (low). The highest mean for science is "In the future, knowing science will help me make money (item 13) and I need to understand science for my job (item 14) with a score of 3.76 (moderate) while the lowest is "I can understand most subjects easily, but science is difficult for me (item 17)" with a score of 3.0 (low). The highest mean for the technological/technical is "I like to imagine creating new thing (item 18)" with a score of 4.02 (high) while the lowest is "I am good at building or repairing something (Item 20)" with a score of 3.47 (moderate). The highest mean 21 st-century skill is "I like to help others so that they can do their best (item 30)" with a score of 4.02 (high) while the lowest is "I can use my time wisely when working alone (item 39) and I usually act responsibly (item 33)" with a score of 3.61 (moderate).

In grade 6, the highest mean for math is "Mathematics is an important subject for everyday life (item 1)" with a score of 4.0 (moderate) while the lowest is "My math score was the worse than the other subjects (item 4)" with a score of 2.70 (low). The highest mean for science is "I feel comfortable when I study Science with (item 10)" with a score of 4.05 (high) meanwhile the lowest is "I can understand most subjects easily, but science is difficult for me (item 17)" with a score of 2.70 (low). The highest mean for technological/technical is "I want to be creative in my future work (item 26)" with a score of 4.16 (high) while the lowest is "I will choose a job that involves building activities or producing works of something (item 25)" with a score of 3.28 (moderate). The highest mean for 21st-century skill is "I like to help others so that they can do their best (item 30)" with a score of 4.24 (high) while the lowest is "I respect all children at my age even differ from me (item 34)" with a score of 3.24 (moderate). Table 9 shows the dimensions that show significant differences in students' attitude toward STEM and 21st-century skills based on grade.

Table 8. Students' attitude toward STEM and 21st-century skill based on grade

\begin{tabular}{|c|c|c|c|c|c|c|c|}
\hline \multirow{2}{*}{ Item } & \multicolumn{3}{|c|}{ Grade } & \multirow{2}{*}{ Item } & \multicolumn{3}{|c|}{ Grade } \\
\hline & 4 & 5 & 6 & & 4 & 5 & 6 \\
\hline 1 & 3.95 & 4 & 4 & 22 & 3.55 & 3.73 & 3.51 \\
\hline 2 & 2.55 & 2.8 & 2.7 & 23 & 3.53 & 3.73 & 3,4 \\
\hline 3 & 2.86 & 2.97 & 2.66 & 24 & 3.79 & 3.79 & 3,4 \\
\hline 4 & 2.95 & 2.79 & 3.03 & 25 & 3.34 & 3,7 & 3.28 \\
\hline 5 & 4.00 & 4.05 & 3.88 & 26 & 3.95 & 3.97 & 4.16 \\
\hline 6 & 2.90 & 3.17 & 3.00 & 27 & 4 & 3.97 & 4.05 \\
\hline 7 & 3.32 & 3.44 & 3.41 & 28 & 4.06 & 4.00 & 4.24 \\
\hline 8 & 3.81 & 3.50 & 3.70 & 29 & 3.53 & 3.82 & 3.54 \\
\hline 9 & 3.11 & 3.26 & 3.03 & 30 & 4.06 & 4.02 & 4.24 \\
\hline 10 & 3.62 & 3.67 & 4.05 & 31 & 3.86 & 3.76 & 3.88 \\
\hline 11 & 2.90 & 3.17 & 3.13 & 32 & 3.90 & 3.85 & 3.94 \\
\hline 12 & 3.53 & 3.67 & 3.47 & 33 & 3.58 & 3.61 & 3.77 \\
\hline 13 & 3.37 & 3.76 & 3.58 & 34 & 4.02 & 3.82 & 3.40 \\
\hline 14 & 3.37 & 3.76 & 3.60 & 35 & 3.93 & 3.79 & 3.64 \\
\hline 15 & 3.55 & 3.50 & 3.75 & 36 & 3.81 & 3.85 & 3.94 \\
\hline 16 & 3.53 & 3.55 & 3.66 & 37 & 3.88 & 3.91 & 3.98 \\
\hline 17 & 2.53 & 3.00 & 2.70 & 38 & 3.55 & 3.79 & 3.71 \\
\hline 18 & 3.60 & 4.02 & 3.98 & 39 & 3.62 & 3.61 & 3.56 \\
\hline 19 & 3.60 & 3.85 & 3.86 & 40 & 3.67 & 3.82 & 4.11 \\
\hline 20 & 3.16 & 3.47 & 3.35 & 41 & 4.04 & 3.97 & 4.13 \\
\hline 21 & 3.72 & $\begin{array}{c}3.82 \\
\text { Overall }\end{array}$ & 3.73 & & $\begin{array}{c}3.57 \\
\text { (high) }\end{array}$ & $\begin{array}{c}3.65 \\
\text { (high) }\end{array}$ & $\begin{array}{c}3.61 \\
\text { (high) }\end{array}$ \\
\hline
\end{tabular}


Table 9. Manova test based on grade

\begin{tabular}{llccc}
\hline & Effect & Value & F & Sig. \\
\hline Grade & Pillai's Trace & .058 & .919 & .501 \\
& Wilks' Lambda & .943 & $.913^{\mathrm{a}}$ & .506 \\
& Hotelling's Trace & .060 & .908 & .511 \\
& Roy's Largest Root & .041 & $1.256^{\mathrm{c}}$ & .291 \\
\hline
\end{tabular}

Table 7 infers that the dimensions showing significant differences are technology and engineering. Although the value of the effect size found is quite small, Cai, Fan, and Du [18] also concluded that men have a better attitude towards the use of technology than women. This finding is similar to Han [19] where male students with positive attitudes towards technology-based learning are more likely to choose STEM majors, while female students are indirectly influenced by belief in the benefits of STEM. Male students who attended technical education programs had higher attitudes towards engineering than female students who attended the same program [20].

Based on the Table 8 results of the above data analysis, it appears that the average student attitudes towards STEM and 21st-century skills are at a high level for each class. These results indicate that there is no significant difference in student attitudes towards STEM and 21st-century skills by class. The MANOVA test was also used to prove this result. As shown in the table, the sig value is $>0.05$ so that we can conclude that there is no significant difference by class on students' attitudes towards STEM and 21st-century skills. This finding is similar to Karakaya and Avgin [21] who stated that class differences do not affect students' attitudes towards STEM.

Overall students' attitude toward STEM and 21st-century skill were at moderate level. Beside, attitudes about STEM education have a significant relationship with their perceived proficiency in 21 stcentury skills [22]. Therefore, to become science and technology innovators and be competitive in the 21stcentury, schools need to produce STEM literate and competent in 21st-century skills students [23]. One of the ways to increase students' attitudes and interest in STEM is by implementing STEM education [24]. The application of STEM-based learning in certain subjects can improve student attitudes while helping students develop positive perceptions of STEM [25]. The results of this study are similar to Popa and Ciascai [26] where students are indeed interested in the STEM field. This result is different from Suprapto [27] which shows that the mathematical domain is higher than science, but when viewed from the average score in this study, it is relatively the same. On other hands, math is the lowest dimension. Students appear to have difficulty in mathematics [28], so that their attitudes are lower. This may occur because the problems in mathematics are related to contextual matters [29] or constructing concepts through real contexts [30] and requires critical thinking [31].

Based on the significance value, Table 5 shows that there is no significant effect of students' attitudes on the science and technology dimension toward their 21st-century skills. But according to this result, math gives significant impact on 21 st-century skill. This finding is similar to Nakakoji and Wilson [32] who state that mathematics is very important and supports the development of 21 st-century skills. In addition, the characteristics of mathematics are to develop and apply a mathematical thinking style to solve daily life problems, so that it is very suitable for 21 st-century skills [33]. Mathematical attitudes are aimed at stimulating creative activity and innovation in 21st education [34], so that they are in line with the characteristics of 21 st-century skills. In addition, technological attitudes are also very important for 21 stcentury learning because it is found that students' cognitive concepts in technology or digital literacy are still low [35], [36].

According to gender aspect, this finding is similar to previous study [37] where male students are more interested in future careers in STEM compared to female students. Rehman and Butt [38] also stated that female lose interest and intention to major in STEM. It seems that female are not interested or prefer to avoid STEM which may be due to gender bias so that they are underrepresented in STEM [39]. This attitude of female students has been proven by Sassler, et al. [40] who stated that women have a lower chance of entering STEM jobs than men until controls for college majors are added. In math, previous study [41] also found that more girls in school felt tense doing math problems compared to boys of the same age. It has been found that boys are relatively better at science and math while girls are relatively better at reading than other academic fields, which is why there is a potential for gender differences in STEM education [42].

\section{CONCLUSION}

Overall student attitudes towards Science, Technology/Engineering and Math (STEM) and 21stcentury skills are at a moderate level. Almost all STEM domains are not positively related to 21 st-century skills. Only mathematics domains are positively related to $21 \mathrm{st}$-century skills. There is a significant 
difference in students' attitudes towards STEM and 21st-century skills by gender. The STEM domains that have the most influence based on gender are technology and engineering, where female student lost their interest in engineering domain. In addition, there are no significant differences in students' attitudes towards STEM and 21st-century skills based on grade (4th, 5th, and 6th).

The educational institution should focus on female students and the grade or class of students may be not considered. The limitation of this study is that it only measures the attitudes of elementary school students in the upper class, not measuring the lower class. In addition, there is no explaining what causes student attitudes that are not high towards STEM and 21st-century skills. Further research can be carried out by investigating the causes of students' low attitudes towards STEM and 21st-century skills not only at the primary school level, but also at the middle to high levels.

\section{ACKNOWLEDGEMENTS} University.

This study was supported and funded by Faculty of Teacher Training and Education, Alma Ata

\section{REFERENCES}

[1] K. Y. Lin, H. S. Hsiao, P. J. Williams, and Y. H. Chen, "Effects of 6E-oriented STEM practical activities in cultivating middle school students' attitudes toward technology and technological inquiry ability," Res. Sci. Technol. Educ., vol. 38, no. 1, pp. 1-18, 2020, doi: 10.1080/02635143.2018.1561432.

[2] F. Razali, O. Talib, U. K. A. Manaf, and S. A. Hassan, "Students Attitude towards Science, Technology, Engineering and Mathematics in Developing Career Aspiration," Int. J. Acad. Res. Bus. Soc. Sci., vol. 8, no. 5, pp. 946-960 2018, doi: 10.6007/ijarbss/v8-i5/4242.

[3] J. R. Wieselmann, G. H. Roehrig, and J. N. Kim, "Who succeeds in STEM? Elementary girls' attitudes and beliefs about self and STEM," Sch. Sci. Math., vol. 120, no. 5, pp. 297-308, 2020, doi: 10.1111/ssm.12407.

[4] R. B. Toma and I. M. Greca, "The effect of integrative STEM instruction on elementary students' attitudes toward science," Eurasia J. Math. Sci. Technol. Educ., Vol. 14, no. 4, pp. 1383-1395, 2018, doi: 10.29333/ejmste/83676.

[5] K. M. Paul, A. V. Maltese, and D. Svetina Valdivia, "Development and validation of the role identity surveys in engineering (RIS-E) and STEM (RIS-STEM) for elementary students," Int. J. STEM Educ., vol. 7, art. no. 45, 2020, doi: 10.1186/s40594-020-00243-2.

[6] M. Esmaeili and A. Eydgahi, "The effects of undergraduate project-based courses on student attitudes toward STEM classes," Int. J. Eng. Res. Innov., vol. 6, no. 2, pp. 66-72, 2014.

[7] E. Wiebe, A. Unfried, and M. Faber, "The Relationship of STEM Attitudes and Career Interest," EURASIA J. Math. Sci. Technol. Educ., Vol. 14, no. 10, 2018, doi: 10.29333/ejmste/92286.

[8] J. P. Kennedy, F. Quinn, and T. Lyons, "The Keys to STEM: Australian Year 7 Students' Attitudes and Intentions Towards Science, Mathematics and Technology Courses," Res. Sci. Educ., vol. 50, pp. 1805-1832, 2020, doi: 10.1007/s11165-018-9754-3.

[9] S. S. Guzey, M. Harwell, and T. Moore, "Development of an Instrument to Assess Attitudes Toward Science, Technology, Engineering, and Mathematics (STEM)," Sch. Sci. Math., vol. 114, no. 6, pp. 271-279, 2014, doi: 10.1111/ssm.12077.

[10] W. W. M. So, Y. Chen, and S. C. F. Chow, "Primary school students' interests in STEM careers: how conceptions of STEM professionals and gender moderation influence," Int. J. Technol. Des. Educ., 2020, doi: 10.1007/s10798020-09599-6.

[11] M. A. Alsmadi, "Requirements for Application of the STEM Approach as Perceived by Science, Math and Computer Teachers and their Attitudes towards it," EURASIA J. Math. Sci. Technol. Educ., vol. 16, no. 9, 2020.

[12] B. Wahono, P. L. Lin, and C. Y. Chang, "Evidence of STEM enactment effectiveness in Asian student learning outcomes," International Journal of STEM Education, vol. 7, art. no. 36, 2020, doi: 10.1186/s40594-020-00236-1.

[13] S. S. Guzey, T. J. Moore, M. Harwell, and M. Moreno, "STEM Integration in Middle School Life Science: Student Learning and Attitudes," J. Sci. Educ. Technol., vol. 25, pp. 550-560, 2016, doi: 10.1007/s10956-016-9612-x.

[14] K. H. Tseng, C. C. Chang, S. J. Lou, and W. P. Chen, "Attitudes towards science, technology, engineering and mathematics (STEM) in a project-based learning (PjBL) environment," Int. J. Technol. Des. Educ., vol. 23, pp. 87-102, 2013, doi: 10.1007/s10798-011-9160-x.

[15] A. Unfried, M. Faber, and E. Wiebe, "Gender and student attitudes toward science, technology, engineering, and mathematics," Friday Inst. Educ. Innov. North Carolina State Univ., vol. 51, pp. 1-26, 2014.

[16] E. Baran, S. Canbazoglu Bilici, C. Mesutoglu, and C. Ocak, "The impact of an out-of-school STEM education program on students' attitudes toward STEM and STEM careers," Sch. Sci. Math., vol. 119, no. 4, pp. 223-235, 2019, doi: 10.1111/ssm.12330.

[17] A. Unfried, M. Faber, D. S. Stanhope, and E. Wiebe, "The Development and Validation of a Measure of Student Attitudes Toward Science, Technology, Engineering, and Math (S-STEM)," J. Psychoeduc. Assess., vol. 33, no. 7, pp. 622-639, 2015, doi: 10.1177/0734282915571160.

[18] Z. Cai, X. Fan, and J. Du, "Gender and attitudes toward technology use: A meta-analysis," Comput. Educ., vol. 105, pp. 1-13, 2017, doi: 10.1016/j.compedu.2016.11.003. 
[19] S. Han, "Korean students' attitudes toward STEM project-based learning and major selection," Journal of Educational Sciences: Theory \& Practice, Vol. 17, No. 2, 2017, doi: 10.12738/estp.2017.2.0264.

[20] J. K. Lee, S. Shin, A. Rachmatullah, and M. Ha, "The relationship of engineering education accreditation program, gender, and academic year with attitude towards convergence among engineering students: Application of latent class analysis," J. Korean Assoc. Sci. Educ., vol. 37, no. 1, pp. 113-123, 2017.

[21] F. Karakaya and S. S. Avgin, "Effect of demographic features to middle school students' attitude towards FeTeMM (STEM)," J. Hum. Sci., vol. 13, no. 3, 2016, doi: 10.14687/jhs.v13i3.4104.

[22] N. Akcanca, "21st Century Skills: The Predictive Role of Attitudes Regarding STEM Education and ProblemBased Learning,” Int. J. Progress. Educ., vol. 16, no. 5, pp. 443-458, 2020.

[23] L. Ah-Namand and K. Osman, "Integrated STEM Education: Promoting STEM Literacy and 21st Century Learning," in M. Shelley and S. A. Kiray, Eds., Research Highlights in STEM Education. International Society for Research in Education and Science (ISRES), 2018.

[24] E. H. M. Shahali, L. Halim, M. S. Rasul, K. Osman, and M. A. Zulkifeli, "STEM learning through engineering design: Impact on middle secondary students' interest towards STEM," Eurasia J. Math. Sci. Technol. Educ., Vol. 13, no. 5, pp. 1189-1211, 2017, doi: 10.12973/eurasia.2017.00667a.

[25] H. Özcan and E. Koca, "The impact of teaching the subject 'pressure' with STEM approach on the academic achievements of the secondary school 7th grade students and their attitudes towards STEM," Egit. ve Bilim, vol. 44, no. 198, pp. 201-227, 2019, doi: 10.15390/EB.2019.7902.

[26] R. A. Popa and L. Ciascai, "Students' Attitude towards STEM Education," Acta Didact. Napocensia, vol. 10, no. 4, 2017.

[27] N. Suprapto, "Students' attitudes towards STEM education: Voices from Indonesian junior high schools," J. Turkish Sci. Educ., vol. 13, pp. 75-87, 2016.

[28] H. Knipprath et al., "STEM Education in Flanders: How STEM@school Aims to Foster STEM Literacy and a Positive Attitude towards STEM," IEEE Instrum. Meas. Mag., vol. 21, no. 3, pp. 36-40, 2018.

[29] R. Richardo and A. Martyanti, "Developing ethnomathematical tasks in the context of yogyakarta to measure critical thinking ability," J. Phys. Conf. Ser., vol. 1, no. 1188, 2019.

[30] R. Richardo, A. A. Abdullah, A. Martyanti, D. A. Sholihah, and W. Nurshanti, "Learning mathematics through Islamic Nusantara culture: An ethnomathematics study in Indonesia," Ethnomathematics Journal, vol. 1, no. 1, pp. 30-35, 2020.

[31] A. Abdullah, W. Shanti, and D. Sholihah, "Critical thinking ability through experiential learning in the calculus class," J. Phys. Conf. Ser., vol. 1631, no. 1, 2020.

[32] Y. Nakakoji and R. Wilson, "Interdisciplinary Learning in Mathematics and Science: Transfer of Learning for 21st Century Problem Solving at University," J. Intell., vol. 8, no. 3, p. 32, 2020.

[33] Ö. F. Vural and S. Vural, "An Examination of 5th Grade Mathematics Curriculum in Terms of 21st Century Skills," Int. J. Educ. Res. Rev., vol. 6, no. 2, pp. 82-92, 2020.

[34] N. H. A. Hamid and N. Kamarudin, "Cultivating Mathematical Creativity Among Students: Learning for 21st Century Education,” Int. Res. J. Educ. Sci., vol. 4, no. 2, pp. 5-9, 2020.

[35] R. Perdana, J. Jumadi, D. Rosana, and R. Riwayani, "The Online Laboratory Simulation With Concept Mapping and Problem Based Learning (OLS-CMPBL): Is It Effective in Improving Students' Digital Literacy Skills?” $J$. Cakrawala Pendidik., vol. 39, no. 2, pp. 382-394, 2020, doi: 10.21831/cp.v39i2.31491.

[36] R. Perdana, R. Yani, J. Jumadi, and D. Rosana, “Assessing Students' Digital Literacy Skill in Senior High School Yogyakarta," JPI (Jurnal Pendidik. Indones., vol. 8, no. 2, p. 169, 2019, doi: 10.23887/jpi-undiksha.v8i2.17168.

[37] J. Vennix, P. den Brok, and R. Taconis, "Do outreach activities in secondary STEM education motivate students and improve their attitudes towards STEM?" Int. J. Sci. Educ., vol. 40, no. 11, pp. 1263-1283, 2018.

[38] A. Rehman and I. H. Butt, "Elementary School Female Students' Attitude towards STEM," J. Bus. Soc. Rev. Emerg. Econ., vol. 6, no. 2, pp. 511-515, 2020.

[39] C. A. Moss-Racusin, C. Sanzari, N. Caluori, and H. Rabasco, "Gender Bias Produces Gender Gaps in STEM Engagement," Sex Roles, vol. 79, pp. 651-670, 2018, doi: 10.1007/s11199-018-0902-z.

[40] S. Sassler, J. Glass, Y. Levitte, and K. M. Michelmore, "The missing women in STEM? Assessing gender differentials in the factors associated with transition to first jobs," Soc. Sci. Res., vol. 63, pp. 192-208, Mar. 2017, doi: 10.1016/j.ssresearch.2016.09.014.

[41] T. A. Franz-Odendaal, K. A. Blotnicky, and P. Joy, "Math Self-efficacy and the Likelihood of Pursuing a STEMBased Career: a Gender-Based Analysis," Can. J. Sci. Math. Technol. Educ., vol. 20, pp. 538-556, 2020, doi: 10.1007/s42330-020-00105-7.

[42] G. Stoet and D. C. Geary, "The Gender-Equality Paradox in Science, Technology, Engineering, and Mathematics Education,” Psychol. Sci., vol. 29, no. 4, pp. 581-593, 2018, doi: 10.1177/0956797617741719. 